\title{
Problem-based learning in secondary education: Evaluation by a randomized experiment
}

\author{
Kristof De Witte \\ Nicky Rogge
}
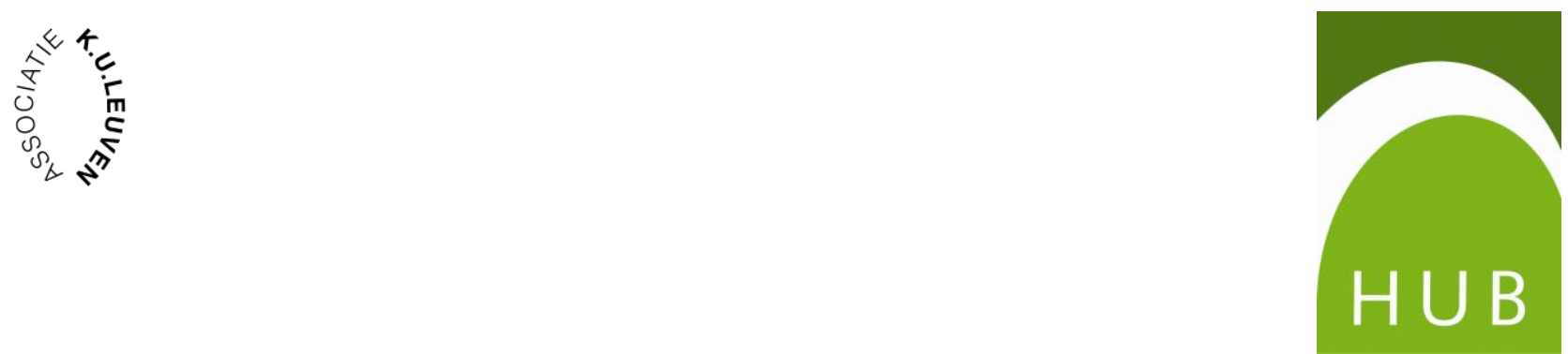


\title{
Problem-based learning in secondary education: Evaluation by a randomized experiment
}

\author{
Kristof De Witte ${ }^{\ddagger \delta 1}$ and Nicky Rogge $\mathrm{e}^{\ddagger *}$ \\ (†): Katholieke Universiteit Leuven (KULeuven) \\ Faculty of Business and Economics \\ Naamsestraat 69, 3000 Leuven (Belgium); \\ (ס): Maastricht University \\ TIER, Faculty of Economics and Business \\ Kapoenstraat 2, 6200 MD Maastricht (the Netherlands) \\ Kristof.dewitte@econ.kuleuven.be \\ and \\ (*): Hogeschool-Universiteit Brussel (HUBrussel) \\ Centre for Economics \& Management (CEM) \\ Stormstraat 2, 1000 Brussels (Belgium)
}

\begin{abstract}
The effectiveness of problem based learning (PBL) in terms of increasing student knowledge and skills has been extensively studied for higher education students and in non-experimental settings. This paper tests the effectiveness of PBL as an alternative instruction method in secondary education. In a controlled randomized experiment, we estimate its effect on tested student attainments, on perceived student attainments, on autonomous and controlled motivation and on class atmosphere. The outcomes indicate a non-significant negative effect on student achievements, a non-significant effect on motivation and a significant positive effect on class atmosphere.
\end{abstract}

Keywords: Problem-based learning; Secondary education; Student achievements; Student motivation; Classroom social climate; Randomized experiment.

JEL-classification: I21; C93

\footnotetext{
${ }^{1}$ Corresponding author. Tel.: 003216326566

E-mail address: Kristof.Dewitte@econ.kuleuven.be
} 


\section{Introduction}

As the literature is realizing that active learning is the key for improved educational attainments, old fashioned instruction methods are replaced for more activating counterparts. Along this line, problembased learning (PBL hereafter) as an activating instruction method is increasingly gaining ground in education. What started as a more practical approach to teach health sciences at the McCaster University in Canada in the late 1960s and subsequently predominantly has been applied in the medical school programs, is recently more and more being promoted by both educational experts and practitioners as an interesting tool to address the major and long-lasting challenges of education (irrespective of the level). It aims at developing skills and habits of life-long, self-directed learning. PBL has predominantly been adopted in colleges and universities - particularly in the medical education programs, but also, though to a lesser extent, in other fields and disciplines such as economics (e.g., Son \& VanSickle, 2000), management (e.g., Joham \& Clarke, 2011), chemistry (e.g., Black \& Deci, 2000) and psychology (e.g., Abrandt Dahlgren \& Dahlgren, 2002). Recently, PBL gained also ground in secondary education (e.g., Gallagher et al.,1992; Mergendoller et al., 2000; Maxwell et al., 2001, 2005). This paper contributes to this expanding literature. In particular, it examines by a randomized experiment the effect of PBL as an alternative instruction method in secondary education on tested educational achievements, perceived educational achievements (i.e., what students think they learnt), motivation and class atmosphere.

Despite its increasing use and popularity, the PBL approach remains controversial. The main reason for this controversy is that, in spite of being the subject of extensive research, several aspects and influences of PBL remain unclear. First of all, there is continuing ambiguity about what PBL exactly stands for. Surely, broadly speaking, we know that it concerns an alternative teaching approach in which students are subdivided into small groups and challenged by a carefully designed problem to start the learning process and to find out what they really know and what knowledge and skills they should know so as to be able to solve the problem. However, in practice, several variations of PBL have been implemented and studied. This makes it a contentious task to define what exactly constitutes PBL. In this paper, we define PBL as "an active learning method that starts from a specific problem. Through group discussion, individual study and collaboration in small groups, students discover their own knowledge, try to understand the underlying mechanisms of the problem and solve the problem together. The teacher acts as a tutor that guides the students and supports the students' initiatives".

Second, it is unclear whether PBL enhances knowledge and skills of students, and whether it increases student motivation and satisfaction. A concern formulated by some researchers, practitioners and teachers is that PBL might not be able to provide students with a sound base of theoretical facts and knowledge. The effectiveness of PBL in terms of increasing student knowledge and skills has been extensively studied in the academic literature for higher education students (particularly in medicinal education programs). The existing evidence for higher education students on the impact of PBL on student test scores is documented in a number of meta-analyses and review studies (e.g., Albanese and 
Mitchell, 1993; Colliver, 2000; Dochy et al., 2003; Gijbels et al., 2005; etc.). Overall, results seem to be rather mixed. Whereas some of the studies reported positive effects of PBL on student test scores, other studies found that PBL-teaching offers no considerable advantages to students in terms of higher gain in knowledge and/or skills. With respect to the effect of PBL on student satisfaction, results show that students in a problem-based learning track are overall more satisfied with their teaching than students in the conventional track. In particular, students who are in a problem-based learning track consider their courses as more nurturing and enjoyable. Recent studies on the association between PBL and student motivation found rather mixed results, with some interviewed students indicating that they believe that PBL has improved their motivation to study and others indicating that the effect of PBL in terms of increasing their studying motivation was non-existent. The paper at hand considers the effects of PBL in secondary education. In particular, it uses PBL as an alternative instruction method during a short time span. To our best knowledge, the literature is silent about the influence on educational attainments, motivation and class atmosphere of PBL as a didactic tool in a short time span (i.e., one teaching hour).

As a third issue, among others, Colliver (2000) noted that most previous studies on the effects of PBL suffer from methodological shortcomings. One of these shortcomings is that in most studies students were non-randomly assigned to the groups of PBL students and the groups in which student were taught according to the conventional manner. Frequently the students had to indicate their preference for the PBL or conventional course. As another shortcoming, schools may have their own criteria to decide on student admission. Both limitations may cause a selection bias in the outcomes. Colliver (2000), for instance, remarked that the effects found in some previous studies might be largely attributable selection bias. Using a randomized experiment, this paper tries to avoid selection effects at school, class and student level.

In sum, this paper contributes to the literature by studying the effects of a PBL instruction tool on student test outcomes, student motivation and class atmosphere in secondary education. Contrary to most previous papers, this study occurs in an experimental setting in which random secondary education schools are participating. In particular, 15 teachers were asked to teach the same course in both PBL- and conventional style in 15 different secondary schools. Within one school, the experiment is evaluated for students in an educational track which is too large to constitute one classgroup (i.e., larger than 30 students) but had to be split (by law) in two class groups. As a priori the two classes are similar, this allows for randomization at pupil level such that selection effects are avoided both at the school, class and student level. Consequently, $2 * 15$ similar classes with a total of 531 students were assigned randomly to the PBL-course and the conventional course. To allow for a meaningful comparison of the PBL-effects over institutions, the 15 teachers were first trained in PBL and provided with guidelines (concerning their role in the teaching process, the format of the problem, etc.) that needed to be strictly followed in the teaching of the PBL-courses.

The paper unfolds as follows. The next section briefly describes the literature on PBL. The focus is mainly on the definition of PBL and the previous findings. A section then follows which introduces 
the experiment as well as the collected data on student test scores, student motivation and student appreciation of the class climate. The ensuing section reports the findings on the relations between PBL and student test scores, motivation, and experience of classroom climate. The paper ends with a summary of the conclusion reached and a discussion of some limitation that could be addressed in future research.

\section{Literature}

\subsection{Key features of problem-based learning}

There is no consensus on a definition of PBL. One reason is that several variations of PBL have been implemented and studied. ${ }^{2}$ Schmidt (1995) made an attempt at providing a general characterization of PBL: "A collection of carefully constructed and engaging 'problems' is presented to small groups of students. These problems usually consist of a description of a set of observable phenomena, situations, or events. ... . The task of the group is to discuss these problems and elaborate on tentative explanations for the phenomena in terms of some underlying process, principle, or mechanisms" (Schmidt, 1995 p. 247).

This definition highlights some key features of PBL. First, PBL is an educational model in which the problem in itself provides a suitable context for subsequent learning. In particular, the core idea is that the problem (e.g., real-life problem tasks, practical case studies, team-based assignments, etc.), when being well-defined and resembling very much the actuality, will suffice to activate the students' interest in the subject-matter. In this respect, PBL associates with relatively new developments in the cognitive psychology, a subdiscipline of the psychology which focuses on exploring the mental processes of people (in terms of how people actively process information: i.e. how they think, solve problems, interpret, etc.) and states that information will be better understood and recalled when it was learned in a situation (i.e., the created problem-setting) which closely resembles the situation in which it will be applied (Norman \& Schmidt, 1992; Schmidt, 1993; Glaser, 1981). Though not mentioned in the definition, Schmidt (1995) emphasized that it is also crucial for PBL that not all information needed to solve the problem is provided to the students.

Second and contrary to conventional methods of teaching in which the teacher directly instructs the students in the content of the course, PBL is student-centred in the sense that the students themselves have a greater input and responsibility in deciding what and how they will learn. In other words, in a PBL setting, students are expected to use a self-directed learning approach to search and gain new relevant information (information which is typically related to existing knowledge). Specifically, students are expected to study the problem, construct an idea of the phenomenon/phenomena that are

\footnotetext{
${ }^{2}$ The complexity of defining PBL is discussed by, among others, Barrows $(1996,1986)$. Barrows remarked that many schools implemented own variations of PBL which typically consist of a mix of conventional and PBLteaching. To help clarify the picture, Barrows (1986) felt it necessary to develop a taxonomy of PBL types.
} 
related with the problem, link the problem under study to prior knowledge, identify the lacunas in their current knowledge and look for new and available sources of knowledge (e.g., in the library, on the internet, etc.).

As a third key feature, all the above occurs on an individual basis as well as in small-group discussions. Among others, Antepohl and Herzig (1999) argued that small groups of students are an essential part of PBL. In the group discussions, students have the opportunity to exchange findings and ideas, look for additional insights and information that enables them to acquire a deeper and better understanding of the problem at hand. Interactions with other students also enable students to acquire more knowledge and skills, learn from each other, and develop social and co-working skills.

Nevertheless, while the definition of Schmidt (1995) is a good attempt at providing a (more or less) standard characterization of PBL, it is incomplete. Several features of PBL are not covered in this definition. A more comprehensive description of the PBL-approach is provided by Barrows (1986, 1996) who listed six basic characteristics of PBL. An example of a characteristic that is less treated in the definition of Schmidt (1995) but that is discussed in the characterization of PBL made by Barrows (1996) is the role of the teacher in PBL. Barrow (1996) described that the teachers play the role of facilitators and guides. In the PBL literature this role is often referred to as "tutor". Typically, the task of the tutor consists in stimulating the group-discussions, monitoring the group interactions (e.g., to avoid free riding of group members), and evaluating the progress.

Before concluding this section, it is important to note that whereas providing a comprehensive definition of PBL is a difficult and complex matter, the same holds for the definition of conventional teaching approaches (as remarked by, among others, Albanese and Mitchell (1994) and Dochy et al. (2003)). That is, even though traditional teaching is typically featured by large-group lectures and teacher-provided learning objectives and assignments, different versions of conventional teaching are applied in practice.

\subsection{PBL and student outcomes}

A major question that inevitably arises in the study of the effects of PBL is whether the PBL-approach offers merits to students in terms of high attainments in knowledge and skills. Unsurprisingly, this is one of the questions which has received most attention in the PBL literature. Some studies indicate that PBL has positive impacts on the students' knowledge and skills, other studies finding more complex results, indicating that PBL students do better in terms of problem solving skills while they do equally good in terms of acquiring knowledge. The results of these studies are analyzed in a number of review studies and meta-analyses. Most of these studies focus on higher education. Examples include Albanese and Mitchell (1993), Vernon and Blake (1993), Berkson (1993), Colliver (2000), Dochy et al. (2003), Gijbels et al. (2005), and Dignath et al. (2008). 
The review study of Colliver (2000) scrutinizes, among other things, the main findings of Albanese and Mitchell (1993), Vernon and Blake (1993), Berkson (1993). Colliver (2000) discussed that whereas these three studies differ greatly in their approach of studying the previous PBL literature (Albanese and Mitchell (1993) listed and categorized the results of quantitative studies, Vernon and Blake (1993) perform a meta-analysis on previous studies, and Berkson (1993) followed a traditional, narrative approach), they all came to a similar conclusion: that is, whereas some of these studies reported some positive effects of PBL on student test scores (and, thus, on students knowledge and/or skills), at best these effects are only small. Moreover, Colliver (2000) remarked that the positive effects of PBL on test scores may be attributable to selection bias (as most reviewed studies are nonrandomized).

More recent studies analyze the effects of PBL on several categories of student outcomes. Dochy et al. (2003), for instance, performed a meta-analysis (using both a vote counting and a combined effect size method) to look upon the link between PBL and students' knowledge and knowledge application. They observed (a) a negative impact of PBL on students' knowledge base and (b) a positive and statistically significant effect of PBL on students' knowledge application. ${ }^{3}$ With respect to the former result, Dochy et al. (2003) indicated that this should be treated with caution as it is strongly influenced by outliers. ${ }^{4}$ Gijbels et al. (2005) looked at the impact of PBL on three levels of knowledge (i.e., understandings of the concept, understanding of the principles that link concepts, and linking of concepts and principles to conditions and procedures for application). They found the most positive effects at the level of knowledge which concerns understanding principles that link concepts. Smits et al. (2002) focused particularly on the effects of PBL on student knowledge as found in studies in medical education and concluded that overall the evidence that PBL has positive effects is rather weak.

In sum, previous literature on the effectiveness of PBL in terms of increasing student knowledge (as compared to conventional teaching methods) shows mixed results. With all of this in mind, we therefore concur with Colliver's (2000) conclusion that the empirical results on the effects of PBL on student knowledge are rather disappointing, "providing no convincing evidence for the effectiveness of PBL, at least not the magnitude of effectiveness that would be hoped for with a major curriculum intervention" (Colliver, 2000, p. 264). In his opinion, the education effectiveness of PBL compared with conventional methods therefore remains to be seen.

\subsection{PBL and classroom learning environment}

Previous literature indicated that students in a PBL-track are more satisfied with their teaching and the classroom as a learning environment than students in the conventional track. In particular, students

\footnotetext{
${ }^{3}$ Note that the meta-analysis of Dochy et al. (2003) looked at studies both within and beyond the medical domain.

${ }^{4}$ The Appendix A and B in Dochy et al. (2003) give a detailed overview of the effects of PBL found in the studies considered in the meta-analysis.
} 
which are in a PBL-track consider their lectures/teaching as more nurturing and enjoyable. For instance, Moore-West et al. (1989) looked upon how students perceive and appreciate their learning environment and courses. They found that PBL students rated their experiences higher in terms of flexibility, emotional climate, meaningfulness, nurturance, student interactions, and hospitability. Dochy et al. (2005) reported that students in the PBL tracks were satisfied with the problem solving, applicability, and group discussions aspects of the PBL-based courses. Other studies confirm the latter result (e.g., Percac and Armstrong, 1998; McNaughton and Krentz, 2000).

Nevertheless, PBL students are also identifying aspects of PBL that are less positive. In particular, Struyven et al. $(2008 \mathrm{a}, \mathrm{b})$ showed that while the perceptions of students in the conventional courses were almost uniformly positive, the experiences of students that followed courses with studentactivating teaching approaches were more disperse with both extreme positive and extreme negative perceptions. Students were generally positive about, e.g., the challenging and activating nature of the assignments. They were more negative about the time pressure and workload associated with the assignments, the increased responsibility, and the possibility of group difficulties and lacking cooperation with some group members. Another issue is that PBL-courses tend to encourage competition between students (Moore et al., 1990). On the other hand, Moore-West and O'Donnell (1985) found that conventional students were more stressed than the counterparts in the PBL tracks (even though both the PBL and conventional students were initially found to be equally stressed, that is, before the start of the courses).

To sum up, the findings of previous studies on the impact of PBL on student satisfaction with the teaching approach and the classroom as a learning environment are not consistent. Generally students appreciate very much the group interaction and the challenging and active nature of the problem assignment. However, students also indicate that there are some aspects of PBL which may cause problems (for instance, group difficulties and free-riding, difficulties in time management, etc.).

\subsection{PBL and student motivation}

Self-directed and active learning is believed to engage students in developing a higher level of autonomous study motivation, a larger variety of learning skills, and better learning outcomes. Based on the self-determination theory (Black \& Deci, 2000) and the concepts of autonomous motivation and controlled motivation, Vansteenkiste et al. (2009) distinguished between four motivational profiles of students and found that the 'good quality motivation' group of students (i.e., the students with high autonomous and low controlled motivation) displayed the most optimal learning pattern relative to all other groups of students. It also seems that an active learning environment stimulates students to adopt deeper learning strategies in the study of the course content (Wilson \& Fowler, 2005; Pintrich, 1999). That is, whereas conventional students are typically more studying the course for reproduction, PBL students are more likely to study the course for meaning (with more focus on understanding the material rather than on just being able to memorize the material for the short term). This result was also found at different levels of education (that is, not only in higher education). For 
instance, using a meta-analysis, Dignath et al. (2008) examined the effects of self-regulated learning interventions (e.g., PBL) on students' motivation in primary schools. The results of this analysis showed a considerably positive effect.

However, there are also studies who found more mixed results. Phipps et al. (2001) examined the students' perceptions of cooperative learning (like PBL) and, in particular, the impact of such learning approaches on student motivation. In their study, about half of the students believed that techniques of cooperative learning were rather ineffective in terms of increasing student motivation. That is, approximately one out of two questioned students perceived the active learning approaches to have a positive influence on the student motivation, the other half was not at all convinced from this. So, as with the effects of PBL on student outcomes and student perception and satisfaction with the classroom learning environment, the findings of previous studies on the association PBL-student motivation is not conclusive.

Due to selection bias and the non-random assignments of schools, previous findings should be interpreted with caution. Moreover, most studies focus on higher education from which the results can not straightforwardly be generalized to other education levels. To account for these limitations, the next section outlines a randomized experiment in which PBL is employed as an instruction method in secondary education.

\section{Data}

The experiment consists of 15 teachers teaching a course both in PBL and in traditional style at a secondary school in Flanders (a region in Belgium). In particular, each teacher was randomly assigned with a random secondary school in which he or she had to teach a course in PBL and in the traditional format. As mentioned previously, several variations of PBL have been implemented and studied. To avoid that the teachers involved in the experimental study would have different ideas of what exactly constitutes PBL, teachers participated a brainstorm meeting on a definition of PBL before the start of the experiment. The discussion (which took about 4 hours) aimed for a common understanding and wide support on the definition. This resulted in the following characterization of PBL: "PBL is an active learning method that starts from a concrete problem. Through group discussion, individual study and collaboration in small groups, students discover their own knowledge, try to understand the underlying mechanisms of the problem and solve the problem together. The teacher acts as a tutor that guides the students and supports the students' initiatives". Note that in the definition, the role of the teacher in the PBL-courses is rather clearly explained to the 15 teachers involved. The role was defined as one of facilitating the problem-solving process. It was strongly emphasized to the teachers that they should not provide any solutions. Nevertheless, teachers were informed that guiding students to (more) interesting sources of information was allowed. The teachers were strongly encouraged to teach the PBL-version of the course completely consistent with this definition. Moreover, the experiment leaders (i.e., the authors of the paper) checked whether teachers were teaching the PBLversion of the course in a completely consistent way with this definition. The check was based on the 
course preparations (of both instruction methods).

The students in the PBL-groups were presented with a problem that refers to an existing situation or event in the real world and that asks for one or multiple concrete solution(s). They were told that they were expected to study the problem, construct an idea of the phenomenon/phenomena that are related with the problem, link the problem under study to prior knowledge, identify the lacunas in their current knowledge, and look for new and available sources of knowledge (e.g., in the library, on the internet, etc.). All of this occurs in small-group discussions.

The experimental and control group classes are classes of the same size and in which students are randomly assigned by the school management. In particular, the experiment is evaluated for students in an educational track which is too large to constitute one class-group (i.e., larger than 30 students) but had to be split (by law) in two class groups. It is clear that the students are randomly assigned to one of the two class groups such that all background variables, including student ability and motivation, should be comparable across both groups. Therefore, selection effects are avoided both at the school, class and student level.

In total, over the 15 secondary schools, PBL-based courses grouped 260 students whereas the traditional lecture-based courses consisted of 271 students. This means that in total 531 students participated in the experiment. The students in the PBL-based classes were further subdivided into small groups of 4 to 5 students. This is completely according to the PBL-approach which states that students should co-operate in small groups. Respectively $66.1 \%$ and $33.9 \%$ of the students are girls and boys. The average age of the participating students is 17.21 years (stdv. $=1.46)$. The majority of the participating students $(77.6 \%)$ are in the final two years of secondary school. The remaining $22.4 \%$ of the students are predominantly in the third and fourth year of secondary school. Some descriptive statistics on the student characteristics for both the PBL- and conventional groups of students are listed in Table 1. The results (by a t-test) indicate that the control and experimental group are well comparable. That is, the composition of the experimental and control class groups are, overall, rather similar (in terms of gender, age, class size, etc.).

[Table 1 about here]

Note that Table 1 also displays summary information on the student test scores, student motivation and student appreciation of the class atmosphere in both the control and experimental group. To measure the gain in student knowledge, both before and after the course, students were asked to complete multiple choice questions to test for their factual knowledge on the subject-matter. Besides this formal test of added value in educational attainments, we asked by a questionnaire to which extent the students thought they have learnt a lot during the PBL or traditional course. It is measured by a likert-type variable which could range from 'I learnt nothing' till 'I learnt very much'. This provides us with an indication on the perceived educational attainments. 
Students were also asked about their motivation for studying and, in particular, whether he/she is autonomously (cf. intrinsic) or controlled (cf. extrinsic) motivated for studying. To measure the student's motivation on a scale, the Academic Self-Regulation Scale after Vansteenkiste et al. (2009) was used. This questionnaire consists of 16 items which measure the students' motivation for studying. In particular, each item provided students with a possible motivation for studying. The students were asked to indicate to what level this motivation applies to their study behaviour (i.e., each item was measured using a 5-point Likert scale with rates varying from "1: completely not important" to " 5 : very important"). Of these 16 items, 8 items are used to measure the students' autonomous motivation for studying. These items provide reasons for studying that are characterized by a feeling of choice and an own will to study. Examples of possible reasons for studying include: 'because it is personally important to me' and 'because I want to learn new things'. The other 8 items are employed to measure the level of controlled motivation for studying. These items provide students with reasons for studying that are characterized by a feeling of obligation and/or pressure. Examples of statements are 'because I'm supposed to do so' and 'because that's something others (parents, friends, etc.) force me to do'. Two principal component analyses are performed to check whether the items that are used to measure respectively autonomous and controlled motivation effectively measure those two types of motivation. The results are presented in Appendix 1 and indicate that for each type of motivation, the resulting principal component explains a satisfactory level of variance. In addition, for both the factor autonomous and controlled motivation, each of the selected items loads sufficiently to the principal component. The summary statistics of the autonomous and controlled motivation components are presented in Table 1.

As a final outcome variable, a questionnaire was also administered to measure the students' perception and appreciation of the class climate during the teaching of the course. In particular, the questionnaire contains 8 items that measure, among other things, the atmosphere in the class during the course, the students' perception of the participation in class, etc. The questionnaire is presented in Appendix 2. The student ratings on the 8 items are aggregated by a simple average into an overall appreciation score.

\section{Findings}

In each of the secondary education schools, students in the PBL-course are compared to students in traditional lecture-based course in terms of their achievements (i.e., student test scores), their perceived learning, autonomous (intrinsic) motivation, controlled (extrinsic) motivation and the atmosphere in the class. As classes and schools were randomly assigned, a causal interpretation can be given to the variable of interest. Students who received a course by an instruction method which follows the PBL-idea receive a value 1(denoted below by 'experimental group'), students in the traditional lecturing receive a value 0 (i.e., the control group). In what follows, we discuss the most important results.

\subsection{Actual and perceived student outcomes}


First consider the causal relationship between PBL and student achievements. The latter are tested by uniform (pre and post-test) tests in the control and experimental group. The results are presented along 4 different model specifications in which we increasingly control for observed heterogeneity. The results are displayed in the left part of Table 2. A first model specification (i.e., Model 1) considers the simple regression of belonging to the experimental group (the control group is reference group) while only controlling for the pre-test on the student achievement. The results indicate that, once controlled for prior knowledge, students in the experimental group obtained significantly less educational attainments than students in the control group. On a test score that ranges from 0 to 10 (with a mean of 7.19), the score decreases in the experimental group by 0.33 in comparison to the control group. In other words, a PBL-inspired lecturing style does not contribute to students outcomes. Quite the contrary, at first sight, it seems that PBL has a negative impact on student knowledge (as measured by the test scores).

[Table 2 about here]

However, this estimated effect fades out if we control for sources of observed heterogeneity. Model 2 includes pupil gender (boys are reference group) and class size. The effect of receiving PBL-based learning stays negative, although non-significant (i.e., non-significant negative estimates of -0.3073 , -0.2372 and -0.1830 for the Models 2-4). Thus, the results from the extended models (accounting for heterogeneity) indicate that the test scores of the students in the PBL-based courses are not significantly different from the scores of the students that followed the traditional courses. Students in our experimental application did not experience any considerable advantage in terms of realizing a higher factual knowledge gain from following the PBL-course compared to their counterparts that were in the traditional course track. As indicated in the literature section, a similar result was also found by several previous studies. In fact, the finding of a non-significant impact of PBL on student learning confirms Colliver's (2000) conclusion, made in the previous section, that the empirical results on the effects of PBL on student knowledge are rather disappointing.

Note in the left part of Table 2 that, as expected, prior educational attainments have a positive significant effect on the achievements. In addition, although females are correlated with lower outcomes, the estimate is not significant. Finally, class size has a significant negative effect on student achievements (with -0.0527 as significantly negative estimate of class size in Model 2). This is in line with some of the previous literature (e.g., Akerhielm, 1995). ${ }^{5}$ The results are robust to further inclusion of heterogeneity. To capture the location of the school, model 3 includes provincial fixed effects. We observe 5 provinces, where a different attitude of students might be present. Model 4 includes class atmosphere and the willingness of the student to intervene during the lecture. Neither of the latter variables have a significant influence on the student achievements, nor do they change previous outcomes.

\footnotetext{
${ }^{5}$ Although, admittingly, there are also several examples of studies that revealed an insignificant relationship between class size and student achievements (e.g., Hanushek, 1997, 1999; Hanushek \& Luque, 2003).
} 
Besides evaluating the impact of problem based learning on what students really have learnt, it is also interesting to examine the effect on what students think they have learnt. The pre-test corresponds to the prior knowledge of the student (i.e., the same pre-test as with actual achievements). The results are listed in the right part of the Table 2. Interestingly, the effect of a PBL inspired instruction method decreases in the perceived learning in comparison to the actual learning. While the former estimate equals -0.10 , it was -0.33 (and statistically significant at the $10 \%$-level) in the latter. In other words, despite students did not learn significantly more in the experimental group, the differences between the control group and experimental group are less pronounced in the perception of the student than in the actual learning process. This observation is constant in the four model specifications.

\subsection{PBL and student motivation}

Table 3 presents the estimated effect of the PBL instruction method on autonomous motivation (left panel, Model 9-12) and controlled motivation (middle panel, Model 13-16). The autonomous motivation, as measured by 8 questions (see the section "Data" as well as Appendix 1), is lower in the experimental group, although this outcome is not significantly different from 0 . More precisely, the four negative estimates of $-0.200,-0.0125,-0.0221$, and -0.0571 are all statistically insignificant. In all four model specifications (model 9-12), the correlation of the pretest with the posttest is significantly positive, which is intuitive. In addition, results indicate that females have a lower autonomous motivation (with in Model 10-12 negative coefficients that are statistically significant at the $10 \%$ - or $5 \%$-level), and also class size influences it negatively (all three estimates have coefficients negative and statistically significant at the $1 \%$-level). As can be observed from model 12, in classes with better atmosphere, the autonomous motivation of students is higher (i.e., estimate 0.1929 significant at the $1 \%$-level). Note, however, that there is in the paper at hand no evidence on the direction of this effect, such that reverse causality cannot be excluded. A similar observation can be made for the activity of the student. In particular, students who do not ask anything if they have a question have in comparison to students who immediately raise their hand if they have a question a significantly lower autonomous motivation.

[Table 3 about here]

The results in Table 3 show that PBL seems to have a non-significant positive impact on controlled motivation. Students in the experimental group increase their controlled motivation in comparison to students in the control group, although not significantly different from 0 (i.e., the estimates of 0.0180 , $0.0267,0.0206$ in the Models 13-15 are all statistically insignificant). This surprisingly contrasts to the estimates of autonomous motivation where a negative coefficient is estimated. The other coefficients (i.e., the estimates for pre-test scores, gender, and class size) are similar to before. 


\subsection{PBL and classroom climate/atmosphere}

Finally, we examine the relationship between PBL and the class atmosphere. The results are displayed in the right panel of Table 3. Students in the experimental group indicate a significant higher class atmosphere (i.e., significant positive estimates of 0.1385 and 0.1251 in the Models 18 and 19). To be more precise, a comparison of the satisfaction rates of the students with several aspects of the course and the class atmosphere shows that, on average, PBL-students are rating the course more positively on a large majority of the questionnaire items. For instance, students reported higher satisfaction on working together in group to solve the problem made, one of the core aspects of PBL.

All other variables have the expected sign. For instance, pre-test scores are positively related to the class atmosphere and class size is found to be negatively related to the class atmosphere. The larger the class, the lower the class atmosphere. In model 18, there is also a negative coefficient for the gender of the students (the estimate of -0.1642 , significant at the $5 \%$-level). This result seems to suggest that females feel a significant lower class atmosphere in comparison to boys. Also observed in Table 3 is the positive coefficient for the atmosphere in class (i.e., coefficient estimate of 0.2981). A better class atmosphere before the start of the PBL-based lecture results in a better atmosphere afterwards. However, as the coefficient is not statistically significant, this interpretation should be treated with caution.

In sum, despite the finding that a PBL-instruction method does not result in higher test scores, it improves the class atmosphere. It can therefore be considered as an interesting alternative didactic tool for secondary education students, rather than an alternative instruction way. Obviously one should take care in generalizing the results. We come back to this issue in the concluding section.

\section{Conclusion and discussion}

Though problem-based learning is increasingly popular in higher education (particularly in medicine education), it is only rarely applied in a secondary education context (although lately, there are more and more applications of PBL in secondary education). This paper tests the effectiveness of PBL as an alternative instruction method in secondary education. In a controlled randomized experiment, we estimate its effect on tested student attainments, on perceived student attainments, on autonomous (cf. intrinsic) and controlled (cf. extrinsic) motivation and on class atmosphere. The experiment covers 15 random secondary schools in Flanders. $2 * 15$ parallel classes with a total of 531 students were randomly assigned to either a control and experimental group. In an experimental group the teacher was teaching the subject using principles of PBL; in a control group he/she was teaching the subject using traditional lecturing. 
The results indicated that students in a PBL course do not obtain higher test results than students in a traditional taught course. On the contrary, the estimated effect turned out to be negative, although for most model specifications not significantly different from 0 . Stated otherwise, on average, students in the PBL-courses did not realize significantly higher or lower test scores compared to the counterparts in the non-PBL courses. PBL does not result in advantages for the students in PBL-courses in terms of acquiring factual knowledge, however, neither does it lead to disadvantages. We also did not observe a difference between the actual test scores and the perceived attainments (i.e., what student think they have learnt). Second, if PBL does not have an effect on educational attainments, it might have on student motivation. In order to examine the association between PBL and student motivation, we distinguished between autonomous (intrinsic) motivation and controlled (extrinsic) motivation. For both types of motivation, we observed non-significant effects of PBL. Controlling for various sources of heterogeneity does not alter the results. Finally, we find a significant positive influence of PBL on class atmosphere. PBL as an instruction method is considered as a welcome change on the traditional lecturing.

Of course, caution is warranted in the interpretation of the results of this study, and this for several reasons. One possible reason for the inconclusive results may be transitional problems associated with the change from conventional courses to PBL-based courses. Among others, O'Hanlon et al. (1995) pointed to this issue. According to this study, it may take some time for both students and teachers to get accustomed with a group-based learning environment. In the current experiment, students had only little time to adjust to the idea and the process of PBL. In this sense, our results can be interpreted as a lower bound estimate as it can be expected that repetition of the instruction method increases the attainments and motivation. As a second issue, the results provided by the multiple choice tests may only provide a partial picture of the gain in student knowledge and skills. One could question whether a multiple choice test is sufficient for assessing the change in student knowledge during the course. The answer is probably not. In order to get a more reliable picture of the student knowledge, it would also be interesting, for instance, to ask students to complete one or more essay questions. Perhaps an examination of more complex knowledge or of other types of knowledge should have been more appropriate. A third reason for why one should be cautious in interpreting the results of this study is that the number of students (531) and the number school institutions (15) participating in this study is rather low. To increase the power of the analysis a larger data set is required. This third issue also results in lower bound estimates. Despite these limitations, the lower bound estimates point to some favourable but often insignificant effects of problem based learning as an instruction method in secondary education. 


\section{Literature}

Albanese, M.A., and Mitchell, S.M. (1993), "Problem-based learning: A review of literature on its outcomes and implementation issues", Academic Medicine, 68(1), pp. 52-81.

Abrandt Dahlgren, M., and Dahlgren, L.O. (2002), "Portraits of PBL: Students' experiences of the characteristics of problem-based learning in physiotherapy, computer engineering and psychology", Instructional Science, 30(2), pp. 111-127.

Akerhielm, K. (1995), “Does class size matter?”, Economics of Education Review, 14(3), pp. 229241.Antepohl, W., and Herzig, S. (1980), "Problem-based learning versus lecture-based learning in a course of basic pharmacology: A controlled, randomized study", Medical Education, 33, pp. 106-113.

Barrows, H.S. (1986), “A taxonomy of problem-based learning methods”, Medical Education, 20, pp. 481-486

Barrows, H.S. (1996), "Problem-based learning in medicine and beyond: A brief overview", New Directions for Teaching and Learning, 68, pp. 3-12.

Berkson, L. (1993), "Problem-based learning: Have expectations been met?", Academic Medicine, 68(10), pp. S79-S88.

Black, A.E., and Deci, E.L. (2000), “The effects of instructors' autonomy support and students' autonomous motivation on learning organic chemistry: A self-determination theory perspective", Science Education, 84(6), pp. 740-756.

Colliver, J.A. (2000), "Effectiveness of problem-based learning curricula: Research and theory", Academic Medicine, 74(3), pp. 259-266.

Deci, E.L., and Ryan, R.M. (2000), "The what and why of goal pursuits: Human needs and the selfdetermination of behavior", Psychological Inquiry, 11(4), pp. 227-268.

Dignath, C., Buettner, G., and Langfeldt, H.-P. (2008), "How can primary school students learn selfregulated learning strategies most effectively? A meta-analysis on self-regulation training programmes", Educational Research Review, 3, pp. 101-129.

Dochy, F., Segers, M., Van den Bossche, P., and Gijbels, D. (2003), "Effects of problem-based learning: A meta-analysis", Teaching and Learning in Medicine, 13, pp. 533-568.

Dochy, F., Segers, M., Van den Bossche, P., and Struyven, K. (2005), "Students' perceptions of a problem-based learning environment", Learning Environments Research, 8(1), pp. 41-66.

Gallagher, S.A., Stepien, W.J., and Rosenthal, H. (1992), "The effects of problem-based learning in problem solving", Gifted Child Quarterly, 36(4), pp. 195-200.

Gijbels, D., Dochy, F., Van den Bossche, P., and Segers, M. (2005), "Effects of problem-based learning: A meta-analysis from the angle of assessment", Review of Educational Research, 75(1), pp. 27-61.

Glaser, R. (1981), "The future of testing: A research agenda for cognitive psychology and psychomentrics", American Psychologist, 36(9), pp. 923-936.

Hanushek, E.A. (1997), "Assessing the effects of school resources on student performance: An update”, Educational Evaluation and Policy Analysis, 19(2), pp. 141-164. 
Hanushek, E.A. (1999), "Some findings from an independent investigation of the Tennessee STAR experiment and from other investigations of class size effects", Educational Evaluation and Policy Analysis, 21(2), pp. 143-163.

Hanushek, E.A., and Luque, J.A. (2003), "Efficiency and equity in schools around the world", Economics of Education Review, 22, pp. 481-502.

Joham, C., and Clarke, M. (2011), "Teaching critical management skills: The role of problem-based learning", Teaching in Higher Education, in press.

Maxwell, N.L., Bellisimo, Y., and Mergendoller, J.R. (2001), "Problem-based learning: Modifying the medical school model for teaching high school economics", The Social Studies, 92(2), pp. 73-78.

Maxwell, N.L., Mergendoller, J.R., and Bellisimo, Y. (2005), "Problem-based learning and high school macroeconomics: A comparative study of instructional methods", The Journal of Economic Education, 36(4), pp. 315-239.

McNaughton, K., and Krentz, C. (2000), "Reflections on constructivist practices in early childhood teacher education", Canadian Journal of Research in Early Childhood Education, 8(2), pp. $7-20$.

Mergendoller, J.R., Maxwell, N.L., and Bellisimo, Y. (2000), "Comparing problem-based learning and traditional instruction in high school economics", The Journal of Educational Research, 93(6), pp. 374-382.

Moore, G.T., Black, S.D., Style, C.B., and Mitchell, R. (1989), "The influence of the new pathway curriculum on Harvard medical students", Academic Medicine, 69, pp. 983-989.

Moore-West, M., Harrington, D.I., Mennin, S.P., Kaufman, A., and Skipper, B.J. (1989), "Distress and attitudes toward the learning environment. Effects of a curriculum innovation", Teaching and Learning in Medicine., 1(3), pp. 151-157.

Norman, G.R., and Schmidt, H.G. (2000), "the psychological basis of problem-based learning: A review of the evidence", Academic Medicine, 67(9), pp. 557-565.

O’Hanlon, A., Winefield, H., Hejka, E., and Chur-Hansen, A. (1995), "Initial responses of first-year medical students to problem-based learning in a behavioural science course: Role of language background and course content", Medical Education, 29, pp. 198-204.

Percac, S., and Armstrong, E.G. (1998), "Introducing a problem-based anatomy course in a traditional curriculum: A Croatian experience”, Medical Teacher, 20(2), pp. 114-117.

Phipps, M., Phipps, C., Kask, S., and Higgins, S. (2001), "University students' perceptions of cooperative learning: Implications for administrators and instructors", Journal of Experiential Education, 24(1), pp. 14-21.

Pintrich, P.R. (1999), "The role of motivation in promoting and sustaining self-regulated learning”, International Journal of Educational Research, 31, pp. 459-470.

Schmidt, H.G. (1995), "Problem-based learning: An introduction", Instructional Science, 22, pp. 247250.

Schmidt, H.G. (1993), "Foundations of problem-based learning: Some explanatory notes", Medical Education, 27, pp. 422-432. 
Schmidt, H.G., Machiels-Bongaerts, M., Hermans, H., ten Cate, T.J., Venekamp, R., Boshuizen, H.P.A. (1996), "The development of diagnostic competence: Comparison of a problem-based, an integrated, and a conventional medical curriculum", Academic Medicine, 71, pp. 658-664.

Smits, P.B.A., Verbeek, J.H.A.M., and De Buisonje, C.D. (2002), "Problem based learning in continuing medical education: A review of controlled evaluation studies", British Medical Journal, 321, pp. 153-432.

Son, B., and VanSickle, R.L. (2000), "Problem-solving instruction and students' acquisition, retention, and structuring of economics knowledge", Journal of Research and Development in Education, 33(2), pp. 95-105.

Struyven, K., Dochy, F., and Janssens, S. (2008a), "Students' likes and dislikes regarding studentactivating and lecture-based educational settings: Consequences for students' perceptions of the learning environment, student learning and performance", European Journal of Psychology of Education, 23(3), pp. 295-317.

Struyven, K., Dochy, F., Janssens, S., and Gielen, S. (2008b), "Students' experiences with contrasting learning environments: The added value of students' perceptions", Learning Environment Research, 11, pp. 83-109.

Vansteenkiste, M., Lens, W., and Deci, E.L. (2006), "Intrinsic versus extrinsic goal contents in selfdetermination theory: Another look at the quality of academic motivation", Educational Psychologist, 41(1), pp. 19-31.

Vansteenkiste, M., Simons, J., Lens, W., Sheldon, K.M., and Deci, E.L. (2004), "Motivating learning, performance, and persistence: The synergistic effects of intrinsic goal contents and autonomysupportive contexts", Journal of Personality and Social Psychology, 87(2), pp. 246-260.

Vansteenkiste, M., Soenens, B., Sierens, E., Luyckx, K., and Lens, W. (2009), "Motivational profiles from a self-determination perspective: The quality of motivation matters", Journal of Educational Psychology, 101(3), pp. 671-688.

Vernon, D.T.A., and Blake, R.L. (1993), "Does problem-based learning work? A meta-analysis of evaluative research", Academic Medicine, 68(7), pp. 550-563.

Walker, A., and Leary, H. (2009), "A problem based learning meta analysis: Differences across problem types, implementation types, disciplines, and assessment levels", Interdisciplinary Journal of Problem-based Learning, 3(1), pp. 6-28. 
Table 1: descriptive statistics $(\mathrm{n}=531)$

\begin{tabular}{|c|c|c|c|c|c|}
\hline & & Average & Stdev. & $\begin{array}{l}\text { t-statistic } \\
\text { difference }\end{array}$ & \\
\hline \multirow[t]{2}{*}{ Gender (dummy: 1 = boys) } & Control & 0.6777 & 0.0283 & & \\
\hline & Experimental & 0.6484 & 0.0290 & 0.7233 & \\
\hline \multirow[t]{2}{*}{ Age } & Control & 17.3300 & 1.2400 & & \\
\hline & Experimental & 17.1000 & 1.6400 & 0.1120 & \\
\hline \multirow[t]{2}{*}{ Year of school } & Control & 5.1500 & 0.9000 & & \\
\hline & Experimental & 4.8900 & 1.3800 & 0.1578 & \\
\hline \multirow[t]{2}{*}{ Class size } & Control & 17.6264 & 0.2897 & & \\
\hline & Experimental & 17.9304 & 0.2887 & -0.7433 & \\
\hline \multirow[t]{2}{*}{ Asking questions } & Control & 1.4884 & 0.0495 & & \\
\hline & Experimental & 1.4144 & 0.0460 & 1.0946 & \\
\hline \multirow[t]{2}{*}{ Pre-test educational attainments } & Control & 5.4286 & 0.1603 & & \\
\hline & Experimental & 5.3577 & 0.1495 & 0.3236 & \\
\hline \multirow[t]{2}{*}{ Post-test educational attainments } & Control & 7.3485 & 0.1403 & & \\
\hline & Experimental & 7.0313 & 0.1403 & 1.5974 & \\
\hline \multirow[t]{2}{*}{ Post-test 'Perceived' attainments } & Control & 3.4962 & 0.0498 & & \\
\hline & Experimental & 3.3755 & 0.0487 & 1.7326 & $*$ \\
\hline \multirow[t]{2}{*}{ Pre-test class atmosphere } & Control & 3.5627 & 0.0593 & & \\
\hline & Experimental & 3.8185 & 0.0538 & -3.1970 & $* * *$ \\
\hline \multirow[t]{2}{*}{ Post-test class atmosphere } & Control & 3.4302 & 0.0562 & & \\
\hline & Experimental & 3.5655 & 0.0576 & -1.6806 & $*$ \\
\hline \multirow[t]{2}{*}{ Pre-test autonomous motivation } & Control & 2.6334 & 0.0461 & & \\
\hline & Experimental & 2.7906 & 0.0432 & -2.4914 & $* *$ \\
\hline \multirow[t]{2}{*}{ Post-test autonomous motivation } & Control & 3.4617 & 0.0441 & & \\
\hline & Experimental & 3.4721 & 0.0444 & -0.1666 & \\
\hline \multirow[t]{2}{*}{ Pre-test controlled motivation } & Control & 2.8073 & 0.0404 & & \\
\hline & Experimental & 2.7625 & 0.0458 & 0.7325 & \\
\hline \multirow[t]{2}{*}{ Post-test controlled motivation } & Control & 2.7202 & 0.0346 & & \\
\hline & Experimental & 2.7764 & 0.0344 & -1.1502 & \\
\hline
\end{tabular}

where $* * *, * *$ and $*$ denote a significant different mean, respectively, at 1,5 and 10\%-level. 
Table 2: Effects of problem based learning on learning

\begin{tabular}{|c|c|c|c|c|c|c|c|c|}
\hline \multirow{2}{*}{$\begin{array}{l}\text { Outcome variable } \\
\text { Variable }\end{array}$} & \multicolumn{4}{|c|}{ Student achievement (tested) } & \multicolumn{4}{|c|}{ Student achievement (perceived) } \\
\hline & Model 1 & Model 2 & Model 3 & Model 4 & Model 5 & Model 6 & Model 7 & Model 8 \\
\hline \multirow[t]{2}{*}{ Experimental group $(\mathrm{pbl}=1)$} & $-0.3283^{*}$ & -0.3073 & -0.2372 & -0.1830 & -0.1035 & -0.1017 & -0.1052 & $-0.1244 *$ \\
\hline & 0.1985 & 0.1978 & 0.1852 & 0.2009 & 0.0706 & 0.0707 & 0.0693 & 0.0715 \\
\hline \multirow[t]{2}{*}{ Pretest (for respective outcome) } & 0.0672 & $0.077 *$ & $0.1006 * *$ & $0.069^{*}$ & 0.0022 & 0.0029 & 0.0165 & -0.0010 \\
\hline & 0.0408 & 0.0408 & 0.0423 & 0.0410 & 0.0143 & 0.0143 & 0.0153 & 0.0143 \\
\hline \multirow[t]{2}{*}{ Gender $($ female $=1)$} & & -0.0864 & -0.2601 & -0.0367 & & -0.1062 & -0.0837 & -0.0921 \\
\hline & & 0.2118 & 0.2027 & 0.2142 & & 0.0751 & 0.0752 & 0.0758 \\
\hline \multirow[t]{2}{*}{ Class size } & & $-0.0527 * *$ & $-0.141 * * *$ & $-0.0629 * * *$ & & -0.0072 & $-0.0215^{* *}$ & -0.0103 \\
\hline & & 0.0206 & 0.0252 & 0.0211 & & 0.0074 & 0.0095 & 0.0076 \\
\hline \multirow[t]{2}{*}{ Atmosphere in class } & & & & -0.1632 & & & & $0.1012 * *$ \\
\hline & & & & 0.1119 & & & & 0.0398 \\
\hline \multicolumn{9}{|l|}{ If I have a question: } \\
\hline \multirow[t]{2}{*}{ (1) I raise my hand during class } & & & & -0.0365 & & & & 0.1629 \\
\hline & & & & 0.3242 & & & & 0.1166 \\
\hline \multirow[t]{2}{*}{ (2) I ask teacher afterwards } & & & & 0.315 & & & & $-0.2047 * *$ \\
\hline & & & & 0.2754 & & & & 0.0979 \\
\hline \multirow[t]{2}{*}{ (3) I don't ask anything } & & & & 2.1796 & & & & -0.2985 \\
\hline & & & & 2.2076 & & & & 0.7947 \\
\hline Constant & $7.0126 * * *$ & $7.9363 * * *$ & $8.6868 * * *$ & $8.6383^{* * *}$ & $3.4561 * * *$ & $3.6496 * * *$ & $3.3751 * * *$ & $3.3777 * * *$ \\
\hline & 0.2613 & 0.4447 & 0.5777 & 0.6351 & 0.0922 & 0.1590 & 0.2185 & 0.2267 \\
\hline Province fixed effects & & & Yes & & & & Yes & \\
\hline Number of observations & 495 & 495 & 495 & 485 & 508 & 508 & 508 & 496 \\
\hline $\mathrm{R}^{2}$-adjusted & 0.0071 & 0.0168 & 0.1416 & 0.0211 & 0.0003 & 0.0025 & 0.0437 & 0.0226 \\
\hline
\end{tabular}


Table 3: Effect of problem based learning on motivation

\begin{tabular}{|c|c|c|c|c|c|c|c|c|c|c|c|c|}
\hline \multirow[t]{2}{*}{ Outcome variable } & \multicolumn{4}{|c|}{ Autonomous motivation } & \multicolumn{4}{|c|}{ Controlled motivation } & \multicolumn{4}{|c|}{ Atmosphere in class } \\
\hline & Model 9 & Model 10 & Model 11 & Model 12 & Model 13 & Model 14 & Model 15 & Model 16 & Model 17 & Model 18 & Model 19 & Model 20 \\
\hline \multirow[t]{2}{*}{ Experimental group $(\mathrm{pbl}=1)$} & -0.0200 & -0.0125 & -0.0221 & -0.0571 & 0.0180 & 0.0267 & 0.0206 & -0.0312 & 0.1278 & $0.1385^{*}$ & $0.1251 *$ & 0.0532 \\
\hline & 0.0614 & 0.0600 & 0.0564 & 0.0592 & 0.0623 & 0.0611 & 0.0577 & 0.0597 & 0.0801 & 0.0770 & 0.0719 & 0.0749 \\
\hline \multirow[t]{2}{*}{ Pretest (for respective outcome) } & $0.2128 * * *$ & $0.2237 * * *$ & $0.2377 * * *$ & $0.1654 * * *$ & $0.1017 * *$ & $0.0998 * *$ & $0.0942 * *$ & $0.0864 * *$ & $0.1691 * *$ & $0.1816^{* * *}$ & $0.1989 * * *$ & 0.0975 \\
\hline & 0.0419 & 0.0410 & 0.0398 & 0.0408 & 0.0445 & 0.0435 & 0.0417 & 0.0424 & 0.0713 & 0.0686 & 0.0658 & 0.0667 \\
\hline \multirow[t]{2}{*}{ Gender $($ female $=1)$} & & $-0.1478 * *$ & $-0.1009 *$ & $-0.1096^{*}$ & & $-0.1357 * *$ & -0.0983 & -0.0994 & & $-0.1642 * *$ & -0.1144 & -0.0967 \\
\hline & & 0.0632 & 0.0605 & 0.0625 & & 0.0646 & 0.0622 & 0.0632 & & 0.0817 & 0.0778 & 0.0795 \\
\hline \multirow[t]{2}{*}{ Class size } & & $-0.0304 * * *$ & $-0.055^{* * *}$ & $-0.0295 * * *$ & & $-0.0291 * * *$ & $-0.0531 * * *$ & $-0.0289 * * *$ & & $-0.0527 * * *$ & $-0.0837 * * *$ & $-0.0505 * * *$ \\
\hline & & 0.0063 & 0.0078 & 0.0063 & & 0.0065 & 0.0080 & 0.0064 & & 0.0082 & 0.0101 & 0.0081 \\
\hline \multirow[t]{2}{*}{ Atmosphere in class } & & & & $0.1929 * * *$ & & & & 0.2089 & & & & 0.2981 \\
\hline & & & & 0.0328 & & & & 0.0329 & & & & 0.0415 \\
\hline \multicolumn{13}{|l|}{ If I have a question: } \\
\hline \multirow[t]{2}{*}{ (1) I raise my hand during class } & & & & 0.0868 & & & & 0.1335 & & & & 0.0686 \\
\hline & & & & 0.0979 & & & & 0.0983 & & & & 0.1234 \\
\hline \multirow[t]{2}{*}{ (2) I ask teacher afterwards } & & & & $-0.1774 * *$ & & & & $-0.2291 * * *$ & & & & $-0.2857 * * *$ \\
\hline & & & & 0.0787 & & & & 0.0794 & & & & 0.0994 \\
\hline \multirow[t]{2}{*}{ (3) I don't ask anything } & & & & 0.0042 & & & & -0.0170 & & & & 0.2307 \\
\hline & & & & 0.6699 & & & & 0.6778 & & & & 0.8474 \\
\hline Constant & $2.8989 * * *$ & $3.5002 * * *$ & $3.0628 * * *$ & $2.9523 * * *$ & $3.1744 * * *$ & $3.7775 * * *$ & $3.4283 * * *$ & $3.077 * * *$ & $2.9691 * * *$ & $3.9675^{* * *}$ & $3.3485^{* * *}$ & $3.1025 * * *$ \\
\hline & 0.1188 & 0.1608 & 0.1952 & 0.2020 & 0.1325 & 0.1770 & 0.2100 & 0.2164 & 0.2020 & 0.2430 & 0.2822 & 0.2812 \\
\hline Province fixed effects & & & Yes & & & & Yes & & & & Yes & \\
\hline Number of observations & 531 & 531 & 531 & 518 & 531 & 531 & 531 & 518 & 526 & 526 & 526 & 513 \\
\hline $\mathrm{R}^{2}$-adjusted & 0.0429 & 0.0906 & 0.2012 & 0.1499 & 0.0061 & 0.0485 & 0.1545 & 0.1295 & 0.0123 & 0.0898 & 0.2089 & 0.1795 \\
\hline
\end{tabular}


Appendix 1: Principal component analyses of items of autonomous and controlled motivation

\begin{tabular}{|c|c|c|c|c|}
\hline & $\underline{\text { Factor loading }}$ & $\underline{\text { mean }}$ & $\underline{\text { Stdev. }}$ & $\underline{\alpha(\text { if item removed) }}$ \\
\hline \multicolumn{5}{|l|}{$\underline{\text { Component 'autonomous motivation }}$} \\
\hline - 'Because I want to learn new things' & 0.56 & 3.36 & 0.90 & 0.87 \\
\hline - 'Because it is personally important to me' & 0.75 & 3.11 & 0.98 & 0.85 \\
\hline - 'Because this represents a meaningful choice to me' & 0.67 & 3.25 & 1.04 & 0.86 \\
\hline - 'Because this is an important life goal to me' & 0.60 & 3.31 & 1.06 & 0.87 \\
\hline - 'Because I am highly interested in doing this' & 0.80 & 2.46 & 0.88 & 0.85 \\
\hline - 'Because I enjoy doing it' & 0.80 & 1.92 & 0.93 & 0.85 \\
\hline - 'Because it's fun' & 0.82 & 1.90 & 0.92 & 0.85 \\
\hline \multicolumn{5}{|l|}{ - 'Because it's an exciting thing to do' } \\
\hline \multicolumn{5}{|l|}{$\underline{\text { Component 'controlled motivation' }}$} \\
\hline - 'Because I'm supposed to do so' & 0.61 & 3.41 & 1.02 & 0.77 \\
\hline $\begin{array}{l}\text { - 'Because that's something others (parents, friend, } \\
\text { etc.) force me to do' }\end{array}$ & 0.73 & 2.61 & 1.20 & 0.75 \\
\hline $\begin{array}{l}\text { - 'Because others (parents, friend, etc.) oblige me to do } \\
\text { so' }\end{array}$ & 0.74 & 2.70 & 1.23 & 0.75 \\
\hline $\begin{array}{l}\text { - 'Because that's what others (parents, friend, etc.) } \\
\text { expect me to do' }\end{array}$ & 0.71 & 3.19 & 1.13 & 0.75 \\
\hline - 'Because I want others to think I'm smart' & 0.52 & 2.68 & 1.10 & 0.77 \\
\hline - 'Because I would feel guilty if I didn’t study' & 0.51 & 2.63 & 1.12 & 0.78 \\
\hline - 'Because I would feel ashamed if I didn't study' & 0.60 & 2.36 & 1.11 & 0.76 \\
\hline - 'Because I want others to think I'm a good student' & 0.59 & 2.54 & 1.06 & 0.76 \\
\hline
\end{tabular}


Appendix 2: Student questionnaire of class climate/atmosphere

1. During the course $I$ found the atmosphere in the classroom:

Very bad $1123 \quad 3 \quad 4 \quad 5$ Very good

2. During the course when I understood something wrong:

1. I raised my hand and asked for more explanation

2. I went to the teacher after class and asked for more explanation

3. I did nothing

3. During the course, time passes most quickly for me when:

1. The teacher is teaching him/herself.

2. We are solving problems in groups.

3. We are doing the exercises individually before discussing the results in class.

4. As a class, we cooperate best when:

1. The teacher is teaching him/herself.

2. We are solving the problems in groups.

3. We are doing the exercises individually before discussing the results in class.

5. If I disagree with the teacher/group or I have a comment then:

1. I say that immediately

2. I wait until after class and tell it to the teacher/person in the group

3. I remain silent

6. Working together in group to solve the problem made that:

1. I got to know my fellow students better and feel better in class.

2. I have more trouble to understand the content of the course.

3 . incongruence arose between the group members.

7. If the teacher teaches in the traditional way then :

1. I can easily follow without having fellow students disturbing me.

2. I talk with fellow student about how they experienced the course after class.

3. there is at least no turmoil as we don't have to work together in group.

8. Overall, I learnt from this course:

Nothing $1223 \quad 4 \quad 5$ A lot 